\title{
Adsorption of Fluoride from Aqueous Solution Using Low-Cost Bentonite/Chitosan Beads
}

\author{
Yi Zhang ${ }^{1}$, Dongfeng Wang ${ }^{1}$, Bingjie Liu ${ }^{1}$, Xiang Gao ${ }^{1}$, Wei Xu ${ }^{1}$, Peng Liang ${ }^{2}$, Ying Xu ${ }^{1 *}$ \\ ${ }^{1}$ College of Food Science and Engineering, Ocean University of China, Qingdao, China \\ ${ }^{2}$ College of Food Science and Technology, Fujian Agriculture and Forestry University, Fuzhou, China \\ Email: yiandzoe@163.com, ${ }^{*}$ xuy@ouc.edu.cn
}

Received April 17, 2013; revised May 18, 2013; accepted June 11, 2013

Copyright (C) 2013 Yi Zhang et al. This is an open access article distributed under the Creative Commons Attribution License, which permits unrestricted use, distribution, and reproduction in any medium, provided the original work is properly cited.

\begin{abstract}
A new adsorbent namely bentonite/chitosan beads has been synthesized and studied for its defluoridation efficiency. Bentonite was activated and the beads were prepared using the inverse suspension polymerization method. The bentonite/chitosan beads (bentonite dosage of $3.0 \mathrm{~g}$ ) showed an adsorption capacity of $0.895 \mathrm{mg} / \mathrm{g}$ whereas chitosan beads had only $0.359 \mathrm{mg} / \mathrm{g}$. The optimal $\mathrm{pH}$ value was observed at $\mathrm{pH} 5$ where the adsorbent reached the maximum defluoridation capacity of $1.164 \mathrm{mg} / \mathrm{g}$. The effect of temperature, contact time and initial fluoride concentration on the adsorption capacity of the adsorbent has also been investigated. Scanning electron microscopy (SEM), energy dispersive X-ray analysis (EDAX) and Fourier-transform infrared spectrometry (FTIR) were used to characterize the adsorbent. The adsorption of fluoride onto the adsorbent followed Freundlich isotherm model and pseudo-second order kinetic model. The fluoride loaded adsorbent could be regenerated using sodium hydroxide.
\end{abstract}

Keywords: Bentonite; Chitosan; Fluoride; Adsorption; Beads

\section{Introduction}

Adsorption technology is an efficient method for fluoride removal from water and has been widely studied [1]. Recent research work has been devoted to develop lowcost adsorbents to enhance the cost effectiveness for defluoridation. For example, chitin composite [2], modified chitosan beads [3], synthetic apatites [4] and bentonite clay [5] have been demonstrated effective adsorbents for fluoride adsorption.

Bentonite is a common group of clay minerals, which is a hydrous aluminium silicate, and it has been reported as an economical material for adsorption of fluoride from water. However, the low adsorption capacity is the major problem for its possible application. Therefore, it is important to modify the bare bentonite to overcome its drawbacks for fluoride removal. Chitosan, also named $\operatorname{poly}(\beta$ 1-4)-2-amino-2-deoxy-d-glucopyranose, is prepared from chitin by partial or total deacetylating. Chitosan is a biopolymer which has been cited as an excellent material for defluoridation from water. However, raw chitosan used in the form of flakes or powder is unstable and the adsorption capacity is minimum [6]. Thus, it is necessary to modify chitosan physically or chemically in order to im-

"Corresponding author. prove its practical use.

The present study deals with the bentonite and chitosan with crosslinker to form an inexpensive and efficient adsorbent. Adsorption equilibrium experiments were used to investigate the adsorption behavior of bentonite/chitosan beads. The effect of various parameters such as bentonite dosage, $\mathrm{pH}$, temperature, initial fluoride concentration and contact time on adsorption capacity of bentonite/chitosan beads was studied. Freundlich isotherm model and Pseudo-second order kinetic model were employed to understand the adsorption process. SEM, EDAX and FTIR analysis were used to characterize the bentonite/chitosan beads before and after fluoride adsorbed. The regeneration experiments were performed to check the reusability of bentonite/chitosan beads for defluoridation.

\section{Materials and Methods}

\subsection{Materials}

All reagents were of analytical grade. Bentonite was supplied by Liuhe Group Co. Ltd. (Qingdao, China). Bentonite was used after activated with hydrochloric acid and calcined in muffle furnace at $500^{\circ} \mathrm{C}$. Chitosan (MW 
$5.1 \times 10^{5} \mathrm{Da}$ and degree of deacetylation 95.4\%) was purchased from Shandong Hecreat marine bio-tech Co. Ltd. (Qingdao, China). Fluoride stock solution of 100 $\mathrm{mg} / \mathrm{L}$ was prepared using anhydrous sodium fluoride. Working fluoride solutions of required concentrations were prepared by appropriate dilution of the stock solution.

\subsection{Preparation of Adsorbent}

The bentonite/chitosan beads was prepared using inverse suspension polymerization [7]. The procedure was: 10.0 $\mathrm{g}$ chitosan and bentonite of required quantities namely $1.0,2.0$ and $3.0 \mathrm{~g}$ were dissolved respectively in $200 \mathrm{~mL}$ acetic acid solution $(2 \%, \mathrm{v} / \mathrm{v})$ for $24 \mathrm{~h}$. Liquid paraffin was added to form a dispersion phase at $50^{\circ} \mathrm{C}$, stirring for $10 \mathrm{~min}$. Then, the system was added with formaldehyde and epichlorohydrin as crosslinker. After that, the beads was washed with petroleum ether, ethanol and deionized distilled water. The wet adsorbent was dried in a vacuum oven at $50^{\circ} \mathrm{C}$. Chitosan beads was prepared without bentonite and served as control.

\subsection{Adsorption Experiments}

Adsorption experiments were carried out with $50.0 \mathrm{~mL}$ of $10 \mathrm{mg} / \mathrm{L}$ fluoride solution at a constant speed of 160 $\mathrm{rpm}$ at $30^{\circ} \mathrm{C}$ for $480 \mathrm{~min}$. Adsorbent of $0.1 \mathrm{~g}$ was added to the fluoride solution. The adsorption of fluoride onto adsorbent was studied under different conditions including $\mathrm{pH}$, temperature, contact time and initial fluoride concentration. After adsorption equilibration, fluoride concentration was measured using a fluoride ion selective electrode (PF-1, Shanghai Leici, China). The amount of fluoride adsorbed was calculated from following equation.

$$
q_{e}=\left(\frac{c_{0}-c_{e}}{w}\right) V
$$

where $q_{e}$ is the adsorption capacity of the adsorbent (mg/g) at equilibrium; $c_{0}$ and $c_{e}$ are the initial and equilibrium fluoride concentrations $(\mathrm{mg} / \mathrm{L})$, respectively; $V$ is the volume of solution (L) and $W$ is the mass of adsorbent $(g)$.

\subsection{Characterization of Adsorbent}

The surface microstructure of the adsorbent was observed with a scanning electron microscope (SEM) and the element composition before and after fluoride adsorption was determined by energy dispersive X-ray analysis (EDAX). In order to confirm the functional groups present in the adsorbent, FTIR spectra of chitosan, bentonite, chitosan beads and bentonite/chitosan beads were recorded on Nexus 470 FTIR spectrometer. The $\mathrm{KBr}$ pelleted samples were scanned over the wavenumber range $400-4000 \mathrm{~cm}^{-1}$ with resolution of $4 \mathrm{~cm}^{-1}$.

\subsection{Regeneration Studies}

Regeneration studies were conducted using sodium hydroxide aqueous solution. The exhausted bentonite/chitosan beads was retrieved in $0.5 \mathrm{M} \mathrm{NaOH}$ for $12 \mathrm{~h}$ and was washed with deionized distilled water followed by drying in oven at $50^{\circ} \mathrm{C}$. The regenerated adsorbent was reused in the next five adsorption experiments.

\section{Results and Discussion}

\subsection{Effect of Bentonite Dosage on Adsorption}

In order to optimize the optimal dosage for bringing down fluoride concentration from aqueous solution, bentonite/chitosan beads with $1.0 \mathrm{~g}, 2.0 \mathrm{~g}$ and $3.0 \mathrm{~g}$ bentonite and raw chitosan beads were used to adsorb fluoride under identical experimental conditions. It can be seen from the results in Figure 1 that the dosage of bentonite in adsorbent significantly influenced the adsorption capacity of adsorbent. Bentonite/chitosan beads with bentonite dosage of $3.0 \mathrm{~g}$ possessed an adsorption capacity of $0.895 \mathrm{mg} / \mathrm{g}$, whereas bentonite/chitosan beads with $2.0 \mathrm{~g}, 1.0 \mathrm{~g}$ and chitosan beads had $0.687 \mathrm{mg} / \mathrm{g}, 0.528$ $\mathrm{mg} / \mathrm{g}$ and $0.359 \mathrm{mg} / \mathrm{g}$, respectively. Hence, $3.0 \mathrm{~g}$ of bentonite was fixed as the optimal dosage in all subsequent experiments.

\subsection{Effect of $\mathrm{pH}$ on Adsorption}

The adsorption data obtained for the effect of different $\mathrm{pH}$ values namely 3, 5, 7 and 9 on defluoridation were shown in Figure 2. The maximum adsorption capacity of $1.164 \mathrm{mg} / \mathrm{g}$ was observed at $\mathrm{pH}$ value of 5 , however the adsorption capacity declined with the increasing of $\mathrm{pH}$ value. Figure 2 also reflected that the acidic $\mathrm{pH}$ could offer more adsorption sites on bentonite/chitosan beads for fluoride removal but the alkaline $\mathrm{pH}$ was undesirable

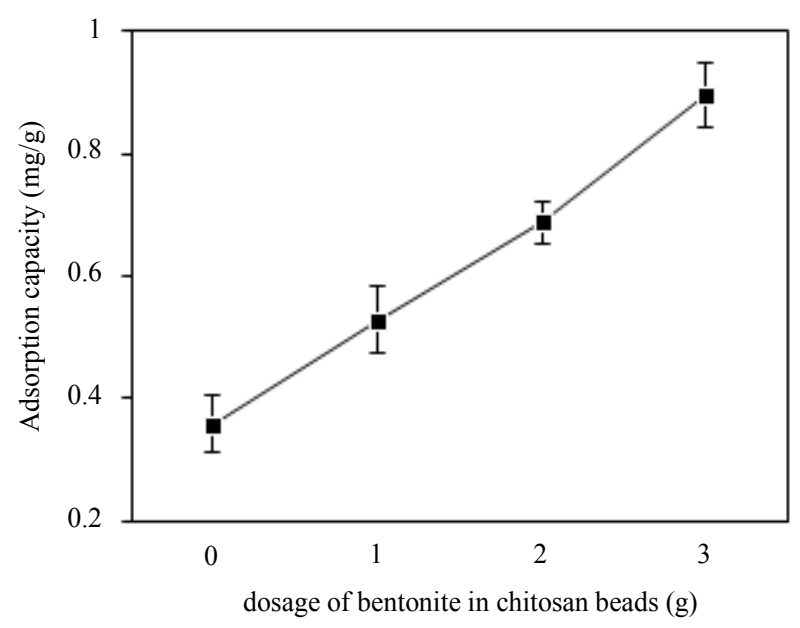

Figure 1. Effect of bentonite dosage on adsorption capacity of adsorbent for fluoride. 


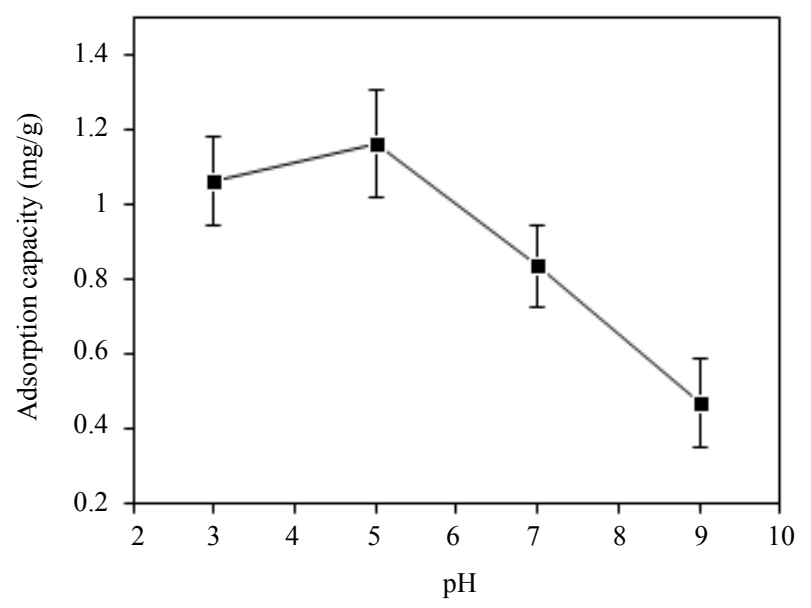

Figure 2. Effect of pH on adsorption capacity of adsorbent for fluoride.

for adsorption process for fluoride.

\subsection{Freundlich Isotherm Model}

The effect of temperature ( $303 \mathrm{~K}, 313 \mathrm{~K}$ and $323 \mathrm{~K})$ and initial fluoride concentration $(2 \mathrm{mg} / \mathrm{L}, 5 \mathrm{mg} / \mathrm{L}, 10 \mathrm{mg} / \mathrm{L}$ and $20 \mathrm{mg} / \mathrm{L}$ ) on adsorption capacity of adsorbent was given in Figure 3(a). The adsorption capacity of bentonite/chitosan beads went up to $1.575 \mathrm{mg} / \mathrm{g}$ at $303 \mathrm{~K}$ with initial fluoride concentration of $20 \mathrm{mg} / \mathrm{L}$. Apparently, the adsorption capacity of adsorbent declined with the rise in temperature, which is perhaps because the high temperature resulted in the unstability of bentonite/ chitosan beads. Figure 3(a) also indicated the initial fluoride concentration could enhance the adsorption of fluoride onto adsorbent.

Freundlich isotherm is a commonly used isotherm model to analyze adsorption data. Freundlich isotherm model can be written as:

$$
\ln q_{e}=\ln K_{f}+\frac{\ln C_{e}}{n}
$$

where $q_{e}$ is the adsorption capacity of adsorbent $(\mathrm{mg} / \mathrm{g})$ at equilibrium and $c_{e}$ is the fluoride concentration in the equilibrium solution $(\mathrm{mg} / \mathrm{L})$. The Freundlich constant $K_{f}$ $(\mathrm{mg} / \mathrm{g})(\mathrm{L} / \mathrm{mg})^{1 / n}$ characterizes the adsorption capacity of adsorbent, and the Freundlich constant $1 / n$ reflects the adsorption intensity of adsorbent.

The fitting curve of Freundlich adsorption isotherm for fluoride adsorption using bentonite/chitosan beads was shown in Figure 3(b) and the Freundlich parameters calculated from fitting curve of Freundlich model were listed in Table 1. The correlation coefficients $\left(R^{2}\right)$ values showed that the adsorption data could be well described by Freundlich isotherm model, which suggested the bentonite/chitosan beads was a heterogeneous adsorbent. The magnitudes of $1 / n$ lying between 0 and 1 suggested

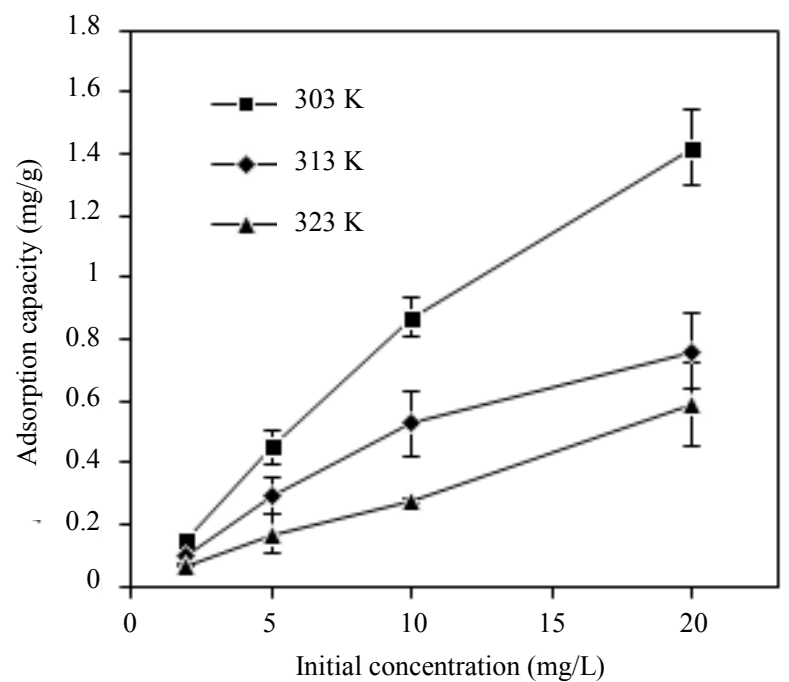

(a)

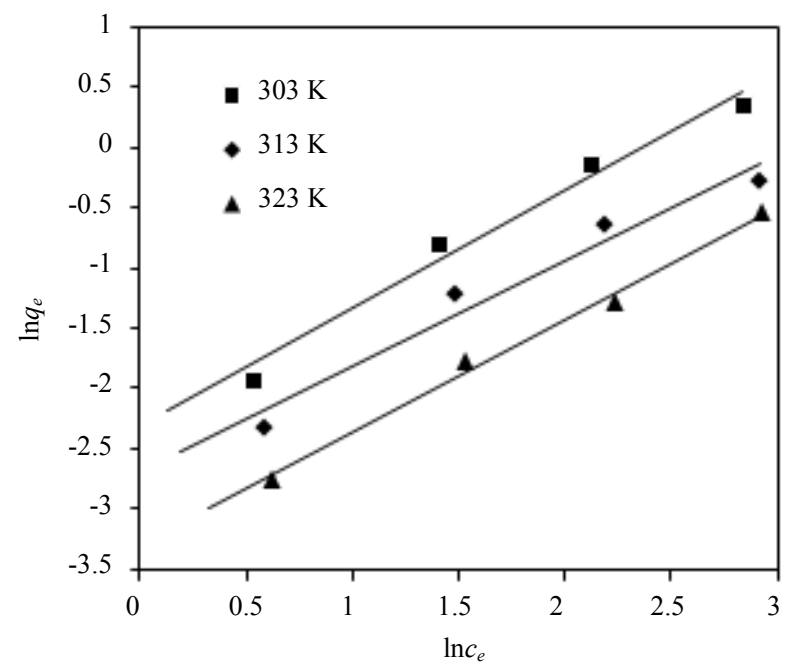

(b)

Figure 3. (a) Effect of temperature and initial fluoride concentration on adsorption capacity of adsorbent; and (b) Fitting curve of Freundlich adsorption isotherm of adsorbent.

Table 1. Freundlich isotherm parameters of adsorbent.

\begin{tabular}{ccccc}
\hline & Temperature & \multicolumn{3}{c}{ Freundlich isotherm } \\
\cline { 3 - 5 }$(\mathrm{K})$ & $1 / n$ & $K_{f}$ & $R^{2}$ \\
\hline & 303 & 0.9847 & 0.0979 & 0.9790 \\
& 313 & 0.8832 & 0.0672 & 0.9636 \\
$\begin{array}{c}\text { Bentonite/chitosan } \\
\text { beads }\end{array}$ & 323 & 0.9365 & 0.0366 & 0.9929 \\
\hline
\end{tabular}

the adsorption of fluoride onto bentonite/chitosan beads was favourable.

\subsection{Pseudo-Second Order Kinetic Model}

The effect of contact time (30 min, $60 \mathrm{~min}, 120 \mathrm{~min}, 240$ 
min and $480 \mathrm{~min}$ ) on adsorption of fluoride using bentonite/chitosan beads was shown in Figure 4(a). The adsorption capacity of adsorbent increased with increasing time and finally reached saturation at around 480 $\min$.

Pseudo-second order kinetic assumes that chemisorption control the adsorption rate [8]. In order to gain the adsorption behavior through the whole range of process, pseudo-second order kinetic model was employed to analyze the adsorption data. The linear form of pseudosecond order kinetic can be expressed as:

$$
\frac{t}{q_{t}}=\frac{1}{K_{2} q_{e}^{2}}+\frac{t}{q_{e}}
$$

where $t$ is the contact time ( $\min ) . q_{t}$ and $q_{e}$ are the amounts of fluoride adsorbed $(\mathrm{mg} / \mathrm{g})$ at arbitary time $t$ and at equilibrium, respectively. $K_{2}$ is the adsorption rate constant (g/mg min).

The plots for pseudo-second order kinetic model of adsorbent was shown in Figure 4(b). The correlation coefficients $\left(R^{2}\right)$ value was larger than 0.9 (Table 2) which suggested the adsorption followed pseudo-second order kinetic model. Thus, the adsorption process of bentonite/chitosan beads for fluoride was governed by both physisorption and chemisorption.

\subsection{Characterization}

The SEM analysis graph (Figure 5) showed that the sizes of bentonite/chitosan beads were between 50 um and 150

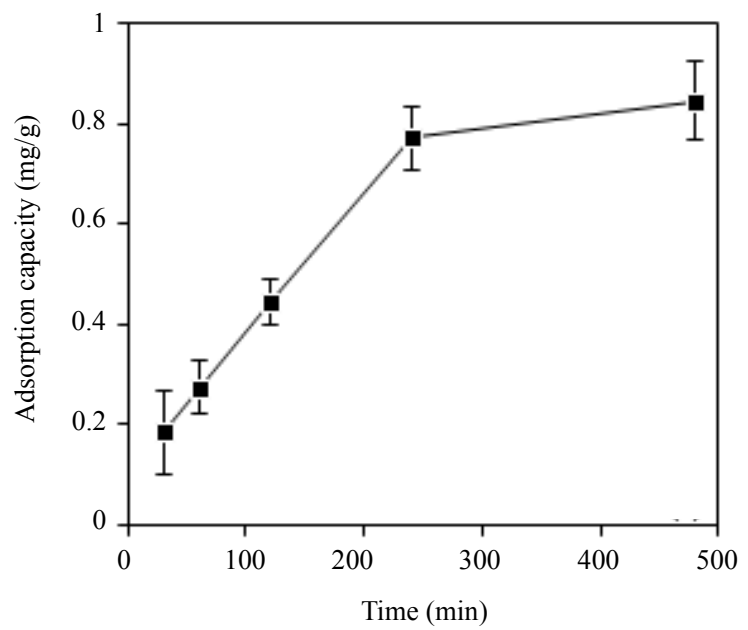

(a) um. The holes on the surface of beads could increase the adsorption sites. The EDAX spectra of the adsorbent (Figure 6(a)) showed the presence of elements in bentonite/chitosan beads. The emergence of fluoride peak in fluoride treated beads (Figure 6(b)) demonstrated the adsorption of fluoride onto adsorbent.

The FTIR spectra of chitosan, bentonite, chitosan beads and bentonite/chitosan beads were compared in Figure 7. The broad band at the region of 3500 - 3200 $\mathrm{cm}^{-1}$ is the overlapping peak of $-\mathrm{NH}_{2}$ and $-\mathrm{OH}$ stretching vibrations [9]. As for chitosan beads (Figure 7(c)), the band at $2925 \mathrm{~cm}^{-1}$ and $2884 \mathrm{~cm}^{-1}$ was the characteristic of $-\mathrm{CH}_{3}$ and $-\mathrm{CH}_{2}$ stretching vibrations, respectively. The adsorption peak at $1649 \mathrm{~cm}^{-1}$ assigned to $-\mathrm{NH}_{2}$ bending vibration. The absorbance peak of symmetric stretching of - $\mathrm{CO}$ on $\mathrm{C}_{3}$ appeared at $1030 \mathrm{~cm}^{-1}$ suggested that $-\mathrm{OH}$ on $\mathrm{C}_{3}$ reacted with crosslinker to form chitosan beads [10]. The FTIR spectrum of bentonite/chitosan beads was given in Figure 7(d), which presented the characteristic of chitosan (Figure 7(a)) and bentonite (Figure 7(b)). Bands at $1399 \mathrm{~cm}^{-1}$ and $519 \mathrm{~cm}^{-1}$ were the -Si-O- stretching and bending vibration, respectively [11]. The FTIR spectra confirmed the successful synthesis of bentonite/chitosan beads.

\subsection{Regeneration of Adsorbent}

The results of regeneration studies shown in Figure 8 indicated the adsorption capacity of adsorbent decreased from $0.92 \mathrm{mg} / \mathrm{g}$ to $0.69 \mathrm{mg} / \mathrm{g}$ with $25 \%$ loss in five

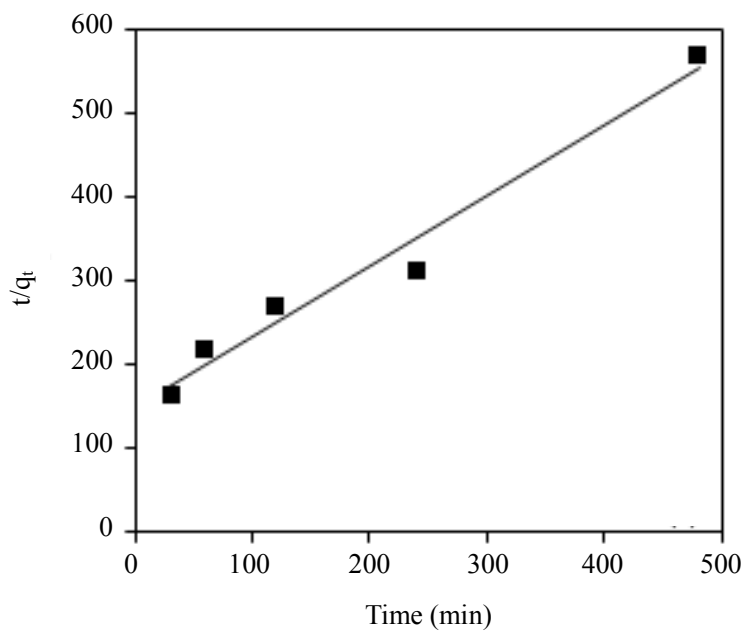

(b)

Figure 4. (a) Effect of contact time on adsorption capacity of adsorbent for fluoride; and (b) Plots for pseudo-second order kinetic model of adsorbent.

Table 2. Pseudo-second order kinetic parameters of adsorbent.

\begin{tabular}{llrr}
\hline & Pseudo-second kinetic equation & $K_{2}$ & $q_{e}$ \\
\hline Bentonite/chitosan beads & $t / q_{t}=0.8417 t+149.67$ & 149.67 & 1.188 \\
\hline
\end{tabular}



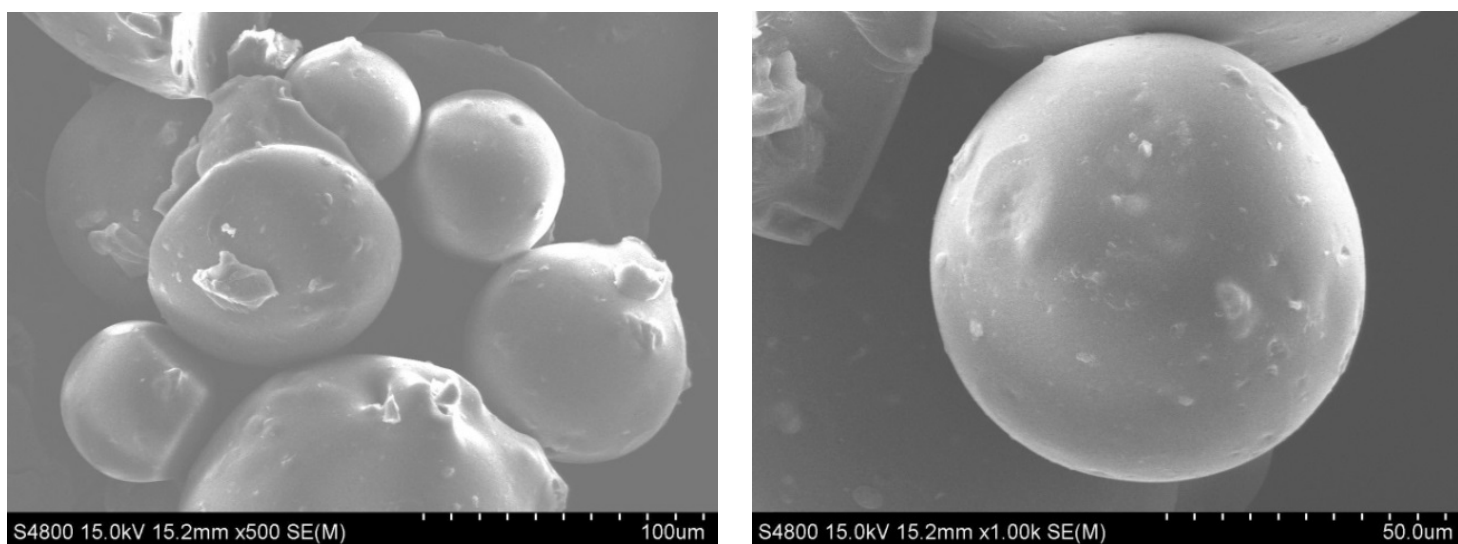

Figure 5. SEM image of adsorbent.

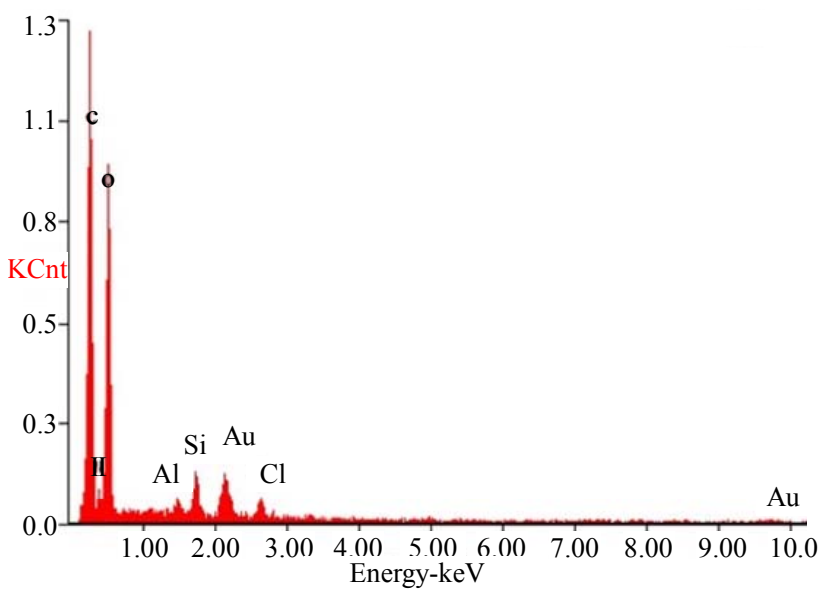

(a)

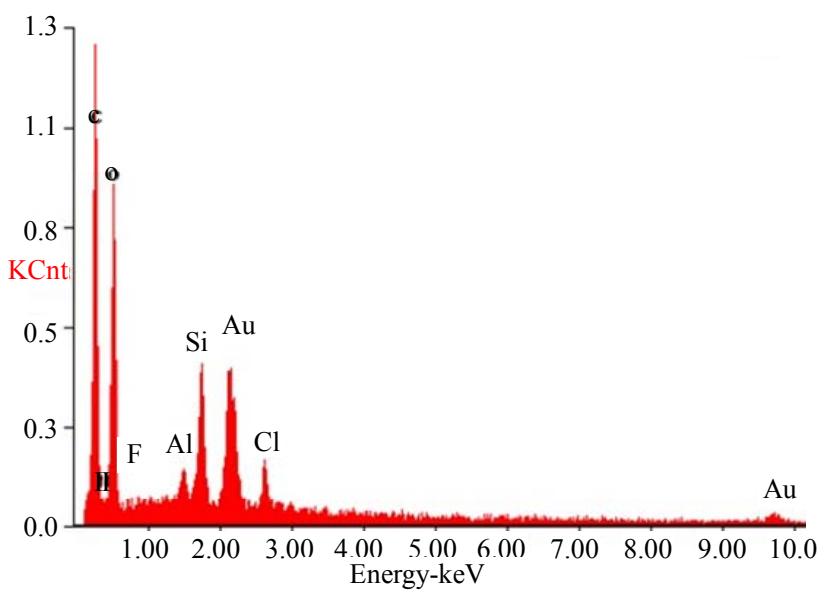

(b)

Figure 6. EDAX spectra of (a) adsorbent and (b) fluoride treated adsorbent.

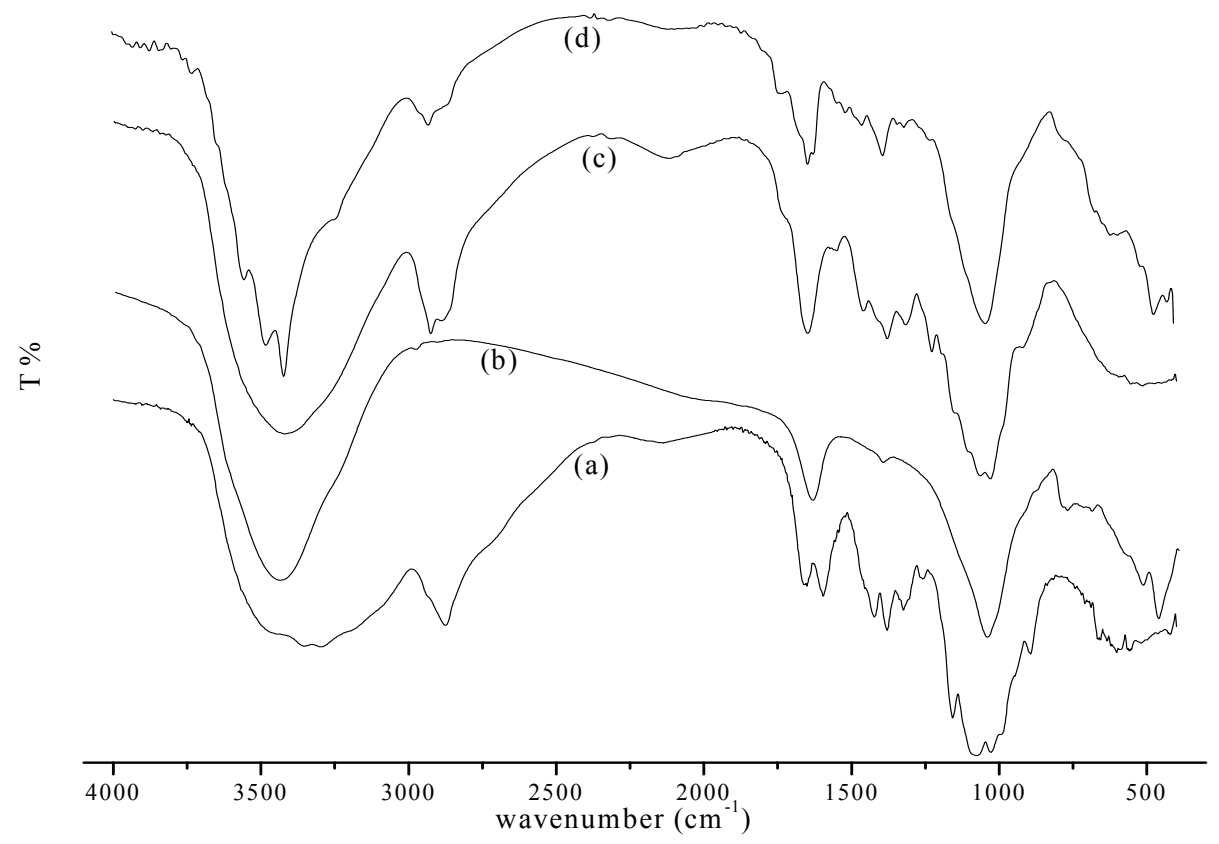

Figure 7. FTIR spectra of (a) Chitosan; (b) Bentonite; (c) Chitosan beads; (d) Bentonite/chitosan beads. 


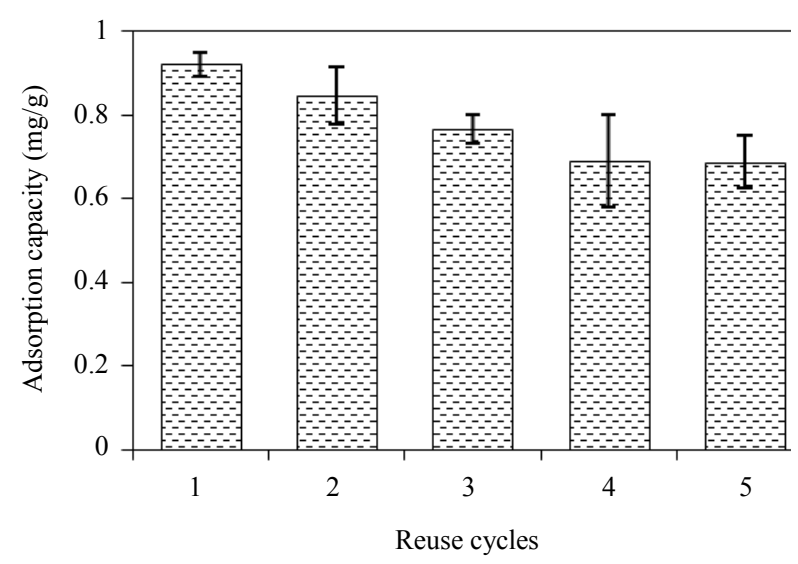

Figure 8. Relationship between reuse cycles and adsorption capacity of adsorbent.

successive adsorption experiments. Therefore, bentonite/ chitosan beads had excellent regeneration ability.

\section{Conclusions}

1) The low-cost bentonite/chitosan beads were successfully prepared for adsorption of fluoride from aqueous solution using inverse suspension polymerization.

2) The optimal dosage of bentonite was $3.0 \mathrm{~g}$ with adsorption capacity of $0.895 \mathrm{mg} / \mathrm{g}$. The optimal $\mathrm{pH}$ value for fluoride adsorption was $\mathrm{pH} 5$ where the adsorption capacity of adsorbent was $1.164 \mathrm{mg} / \mathrm{g}$.

3) The adsorption followed Freundlich isotherm model and pseudo-second order kinetic model.

4) Bentonite/chitosan beads were a low-cost, effective and reusable adsorbent for adsorption of fluoride.

\section{Acknowledgements}

The authors are thankful for the financial support by National Special Fund for Scientific Research on Public Causes (201005020), P.R. China and National Science Foundation of China (31101330).

\section{REFERENCES}

[1] W. Ma, F.-Q. Ya, M. Han and R. Wang, "Characteristics of Equilibrium, Kinetics Studies for Adsorption of Fluoride on Magnetic-Chitosan Particle," Journal of Hazardous Materials, Vol. 143, No. 1, 2007, pp. 296-302.

\section{doi:10.1016/j.jhazmat.2006.09.032}

[2] C. Sairam Sundaram, N. Viswanathan and S. Meenakshi, "Fluoride Sorption by Nano-Hydroxyapatite/Chitin Composite," Journal of Hazardous Materials, Vol. 172, No. 1, 2009, pp. 147-151. doi:10.1016/j.jhazmat.2009.06.152

[3] D. Thakre, S. Jagtap, N. Sakhare, N. Labhsetwar, S. Meshram and S. Rayalu, "Chitosan Based Mesoporous Ti-Al Binary Metal Oxide Supported Beads for Defluoridation of Water," Chemical Engineering Journal, Vol. 158, No. 2, 2010, pp. 315-324. doi:10.1016/j.cej.2010.01.008

[4] A. Yehia and K. Ezzat, "Fluoride Ion Uptake by Synthetic Apatites," Adsorption Science \& Technology, Vol. 27, No. 3, 2009, pp. 337-347. doi:10.1260/026361709789868910

[5] S. P. Kamble, P. Dixit, S. S. Rayalu and N. K. Labhsetwar, "Defluoridation of Drinking Water Using Chemically Modified Bentonite Clay," Desalination, Vol. 249, No. 2, 2009, pp. 687-693. doi:10.1016/j.desal.2009.01.031

[6] P. Miretzky and A. F. Cirelli, "Fluoride Removal from Water by Chitosan Derivatives and Composites: A Review," Journal of Fluorine Chemistry, Vol. 132, No. 4, 2011, pp. 231-240. doi:10.1016/j.jfluchem.2011.02.001

[7] X. Y. Wang, D. F. Wang, P. Liang and X. G. Liang, "Synthesis and Properties of an Insoluble Chitosan Resin Modified by Azamacrocycle Copper(II) Complex for Protein Hydrolysis," Journal of Applied Polymer Science, Vol. 128, No. 5, 2013, pp. 3080-3288. doi:10.1002/app.38461

[8] B. Liu, D. Wang, X. Gao, L. Zhang, Y. Xu and Y. Li, "Removal of Arsenic from Laminaria Japonica Aresch Juice Using As (III)-Imprinted Chitosan Resin," European Food Research and Technology, Vol. 232, No. 5, 2011, pp. 911-917. doi:10.1007/s00217-011-1460-6

[9] N. Viswanathan, C. S. Sundaram and S. Meenakshi, "Removal of Fluoride from Aqueous Solution Using Protonated Chitosan Beads," Journal of Hazardous Materials, Vol. 161, No. 1, 2009, pp. 423-430. doi:10.1016/j.jhazmat.2008.03.115

[10] B. Liu, D. Wang, Y. Xu and G. Huang, "Adsorption Properties of Cd(II)-Imprinted Chitosan Resin," Journal of Materials Science, Vol. 46, No. 5, 2011, pp. 1535-1541. doi:10.1007/s10853-010-4958-6

[11] A. S. Özcan and A. Özcan, "Adsorption of Acid Dyes from Aqueous Solutions onto Acid-Activated Bentonite," Journal of Colloid and Interface Science, Vol. 276, No. 1, 2004, pp. 39-46. doi:10.1016/j.jcis.2004.03.043 